\title{
New species of the genus Dentigaster Zettel (Hymenoptera, Braconidae, Cheloninae) from Brazil
}

\author{
Dias, MM.* and Penteado-Dias, AM. \\ Departamento de Ecologia e Biologia Evolutiva, Universidade Federal de São Carlos - UFSCar, Rod. Washington Luís, \\ Km 235, CP 676, CEP 13565-905, São Carlos, SP, Brazil \\ *e-mail: manoelmd@ufscar.br
}

Received April 2, 2012 - Accepted April 23, 2012 - Distributed May 31, 2013

(With 13 figures)

\begin{abstract}
A new species of the genus Dentigaster Zettel, 1990 (Braconidae, Cheloninae) is described from savannah areas of Mato Grosso, São Paulo and Minas Gerais states, Brazil. This is the fourth species of the genus known for brazilian fauna.
\end{abstract}

Keywords: Cerrado, morphology, taxonomy.

\section{Nova espécie do gênero Dentigaster Zettel (Hymenoptera, Braconidae, Cheloninae) do Brasil}

\section{Resumo}

Uma nova espécie do gênero Dentigaster Zettel, 1990 (Braconidae, Cheloninae) é descrita em áreas de Cerrado dos Estados de Mato Grosso, São Paulo e Minas Gerais, Brasil. Essa é a quarta espécie do gênero conhecida para a fauna brasileira.

Palavras-chave: Cerrado, morfologia, taxonomia.

Dentigaster Zettel, 1990 includes seven neotropical species, three of them occuring in Brazil: Dentigaster barbarella Zettel, 1990, Dentigaster erythrothorax Zettel, 1992 and Dentigaster albifascies Zettel, 1992. The genus belongs to the tribe Pseudophanerotomini Zettel, 1990. The other species from the neotropics are: Dentigaster walteri Zettel, 1990, Dentigaster tenuiventris Zettel, 1990, Dentigaster warana Braet and Fretey, 1997 and Dentigaster brullei Braet and Sharkey, 2012. This last species was described in Sharkey and Braet (2012), including a key to the species of the genus. A new species is now described from cerrado areas of Mato Grosso, São Paulo and Minas Gerais, Brazil. The morphological terms follow Van Achterberg (1993). SEM images of uncoated specimens were taken using a Quanta 250 low vacuum scanning electron microscope. Digital photographs were taken using a Leica DFC 295 camera attached to a Leica Stereomicroscope and captured with LAS Software version 3.7.0. The examined material is deposited in the collection of the Departamento de Ecologia e Biologia Evolutiva, Universidade Federal de São Carlos (DCBU).

Dentigaster lutzi sp. n. Dias and Penteado-Dias

Holotype female (Figures 1-3), body length $6.7 \mathrm{~mm}$, fore wing $4.5 \mathrm{~mm}$.

Diagnosis. Antenna long (52 flagellomeres); brown, with first flagellomere yellowish. Head, pronotum and mesoscutum (except posterior margin) orange; other parts of mesosoma and metasoma, brown. First tergite of metasoma with a prominent knob at anterior margin; second tergite with a yellowish patch basally (Figures 1,3).

Colour. Antenna with scapus and pedicellus brown; first flagellomere yellowish, brown at base; second, yellowish brown, the following brown. Head, propleuron, pronotum, mesoscutum (except posterior margin), orange. Other parts of mesosoma brown, ochreous brown near base of wings and near the medium and posterior coxae. Tegula and humeral plate brown. Fore wing infuscate, more lightly apically and at base, including basal cell; darker infuscate on first submarginal cell, bellow the stigma, and also on marginal and second submarginal cells. Fore wing with transverse white band at level of basal part of stigma. Veins, stigma and parastigma, brown; stigma whitish basally; r-m and veins on transverse white band, white (Figure 2). Hind wing lightly infuscate, with brown veins. Fore leg brown, with coxa orange brown; trochantellus, femur except base and tibia basally yellowish brown. Mid leg brown, with trochantellus, femur apically and tibia basally yellowish brown. Hind leg brown, with tibia basally yellowish brown. Carapace brown; T2 with yellowish patch basally (Figure 3). Ovipositor sheath brown.

Head. Antenna with 52 flagellomeres. Scapus $2.25 \times$ as long as maximally wide, $1.05 \mathrm{x}$ longer than first flagellomere. 

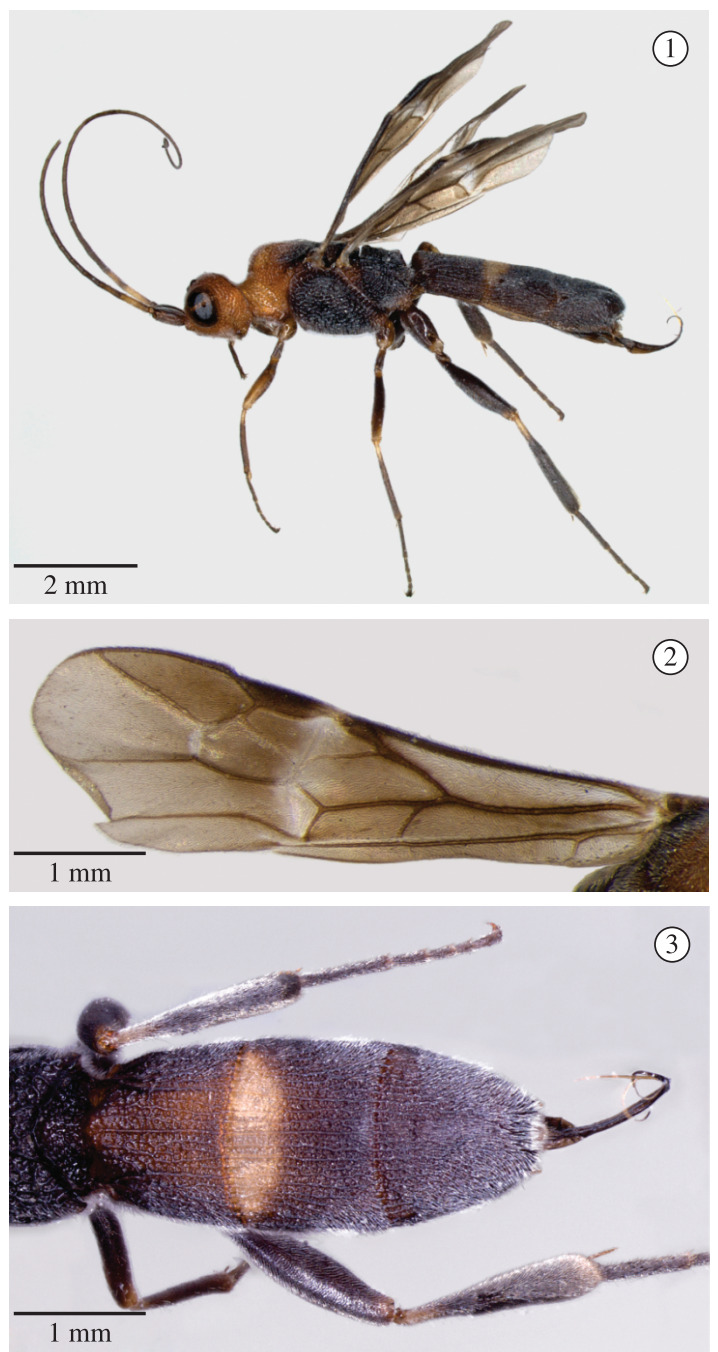

Figures 1-3. Dentigaster lutzi, sp. n., holotype, Itiquira, Mato Grosso. 1) lateral habitus; 2) fore wing; 3) metasoma, dorsal view.

First flagellomere $4.25 \times$ as long as wide, $1.31 \times$ as long as the second one. Penultimate flagellomere as long as wide, $0.06 \times$ as long as first flagellomere, $0.6 \mathrm{x}$ as long as apical flagellomere. Head $1.83 \times$ as wide as its median length. Eye $1.06 \times$ length of temple (in dorsal view), $2.13 \times$ as high as broad, with short and sparse setae. Head coarsely punctate (Figures 4-6). Clypeus flat in lateral view, with convex lower margin, with two blunt teeth; its surface moderately punctate (Figure 4 ). Malar space $0.84 \times$ basal width of mandible, 0.46x eye height (Figure 6). Face convex, with a small median carina. Temple not swollen in dorsal view. Frons concave. POL $0.75 \times$ ocellar diameter, $0.28 \times$ OOL. Occipital carina present, complete (Figure 5), joining hypostomal carina before mandible.

Mesosoma. Mesosoma $1.83 \times$ as long as wide in lateral view, $1.62 \times$ as long as wide in dorsal view. Pronotum coarsely punctate, areolate anteriorly. Mesoscutum anteriorly prominent and rounded, coarsely punctate and posteriorly areolate. Notauli present on anterior half of mesoscutum, moderately evident. Scutellar sulcus with 7 complete carinae; scutellum with surface coarsely punctate (Figure 7). Mesopleuron mostly areolate. Propodeum areolate, with evident carinae; with prominent posterior lateral angles (Figures 8, 9). Metapleuron areolate. Fore wing (Figure 2): stigma $4.43 \times$ as long as wide. Marginal cell distally closed. Vein $\mathrm{r} 0.33 \times$ as long as vein $3-\mathrm{SR}, 0.11 \times$ as long as vein SR1, $0.21 \times$ as long as vein $2-S R$. Vein $1-S R+M$ present. First discal cell $3.75 \times$ as long as wide. Vein r-m present, with a wide bulla. Vein m-cu postfurcal. Vein cu-a of fore wing present, postfurcal. Vein CU $1 b$ postfurcal with m-cu. First subdiscal cell distally closed. Vein 2-1A long. Hind wing: Vein 1-SC+R present. Subbasal cell medium sized. Vein M+CU $0.87 \times$ as long as vein 1-M. Legs: hind coxa large. Hind femur $3.6 \times$ as long as wide. Hind tibia $6.31 \times$ as long as wide, $2.35 \times$ as long as the hind basitarsomere length. Hind basitarsomere $6.50 \times$ as long as wide, $0.84 \times$ as long as tarsomeres 2-5.

Metasoma. Carapace with two transversal areolate sutures (Figures 10, 11). First and second tergites rugoseareolate, with irregular longitudinal striae. Third tergite mostly finely rugose-areolate. First tergite with anterior prominent median knob; first and second tergites with a median longitudinal carina present. First tergite has also two lateral longitudinal carinae (Figures 3, 10, 11). Carapace apically emarginated (Figures 10,13). First tergite $0.83 \times$ as long as apical width. Median length of second tergite $0.77 \times$ its basal width, $0.95 \times$ as long as first tergite. Carapace $2.31 \times$ as long as wide in dorsal view. Third tergite with four irregular carinae apically, partially concealed by setae (Figure 13). Expansion of postero-ventral rim, on third tergite, about one third shorter than the length of the tergite (Figure 12).

Male. Unknown.

Etymology. From the name of our friend João Carlos Marinho Lutz.

Material examined ( 6 females, from Malaise traps). BRAZIL. Mato Grosso: Itiquira, Fazenda Santo Antonio do Paraiso, 8.V. 2000, M. M. B. Lutz and J. C. M. Lutz col. (holotype). Itiquira, Fazenda Michelin, 16.VI. 2006, R. S. Santos col. (paratype). São Paulo: São Carlos, Universidade Federal, campus São Carlos, 18.XI.1998, S. M. P. Braga col. (paratype); idem,14.XII.1998 (paratype). Minas Gerais: São Roque de Minas, Parque Nacional da Serra da Canastra, 4.XI.2009, J. F. Nunes col. (2 paratypes).

Comments. The bicolour pattern, with head and anterior part of mesosoma orange and other parts of mesosoma and metasoma principally brown to blackish, is diagnostic to D. lutzi. Antenna can not present the yellowish areas on the first and second flagellomeres. The legs can be predominantly brown, with yellowish brown areas reduced. On the fore wing, the stigma can 

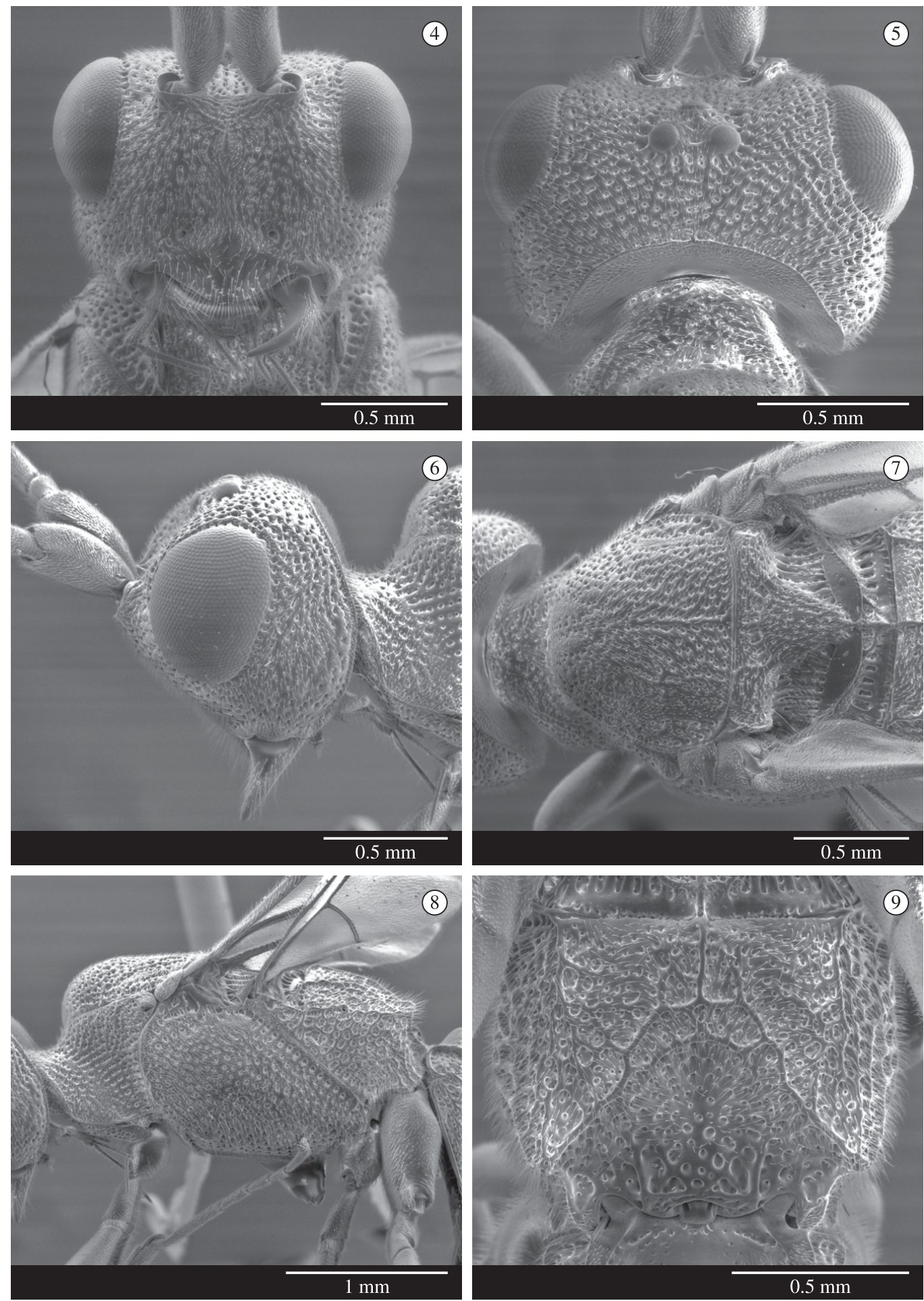

Figures 4-9. Dentigaster lutzi, sp. n., paratype, São Carlos, São Paulo. 4) head, frontal view; 5) head, dorsal view; 6) head, lateral view; 7) mesosoma, dorsal view; 8) mesosoma, lateral view; 9) propodeum, dorsal view.

be all brown or whitish basally. The yellowish patch on $\mathrm{T} 2$ of carapace can be reduced. Among other characters, $D$. lutzi differs from $D$. barbarella and $D$. warana, both with orange head, by: scapus, pedicellus, mesopleuron and metapleuron brown to blackish; prominent anterior median knob on first tergite of metasoma. 

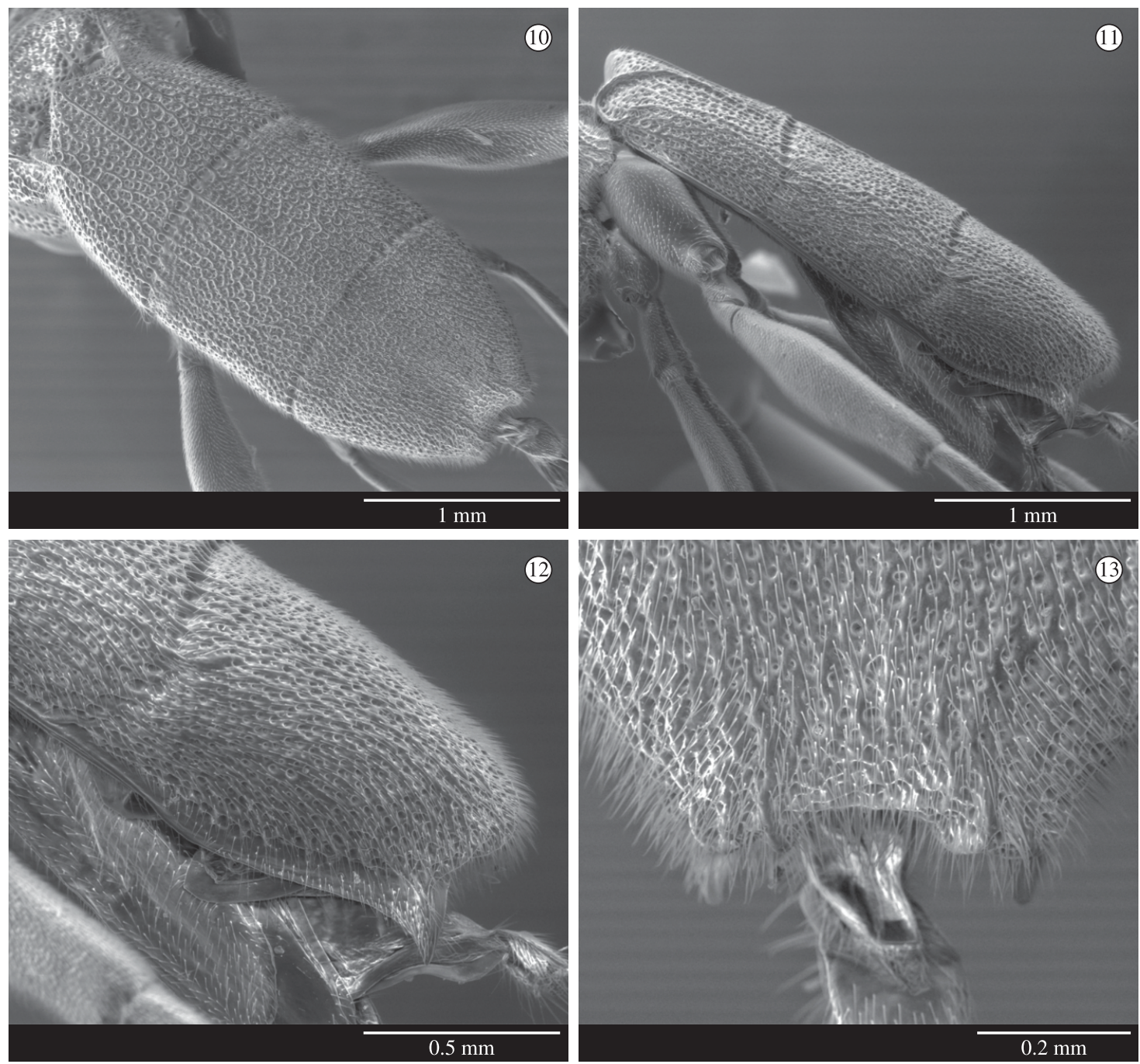

Figures 10-13. Dentigaster lutzi, sp. n., paratype, São Carlos, São Paulo.10) metasoma, dorsal view; 11) metasoma, lateral view; 12) third tergite, lateral view; 13) apex of third tergite, dorsal view.

Acknowledgements - To Marina Moraes Barros Lutz and João Carlos Marinho Lutz, collectors of the holotype, for their contribution to our work. To the Instituto Chico Mendes de Conservação da Biodiversidade for allowing us access to the Parque Nacional da Serra da Canastra. To Jose Fernandez Triana of the Canadian National Collection, Ottawa, Canada and David Wahl, of the American Entomological Institute, Gainesville, USA, for provide images of type material of the Dentigaster species. To Agnièle Touret-Alby of the Muséum National d'Histoire Naturelle, Paris, France, for the loan of the holotype of Dentigaster warana. We were financially supported by the Instituto Nacional de Ciência e Tecnologia dos Hymenoptera Parasitoides da Região Sudeste Brasileira (HYMPAR/Sudeste - CNPq/FAPESP/CAPES).

\section{References}

SHARKEY, M. and BRAET, Y. 2012. New species of the rare genera Dentigaster Zettel, 1990 (Hymenoptera, Braconidae, Cheloninae) and Minanga Cameron, 1906 (Sigalphinae) from French Guyana. Journal of Hymenoptera Research, vol. 25, p. 93-102. http://dx.doi.org/10.3897/jhr.25.2519

VAN ACHTERBERG, C.,1993. Illustrated key to the subfamilies of the Braconidae (Hymenoptera: Ichneumonoidea). Zoologische Verhandelingen, no. 283, 189 p. 